\title{
Interview
}

\section{An interview with James Simpson on translanguaging and ESOL}

\author{
Stefan Vollmer \\ University of Leeds, England
}

Text received 2 March 2017; accepted 3 March 2017; final version 27 March 2017

DOI: http://dx.doi.org/10.5565/rev/jt13.720

The author interviewed Dr. James Simpson of the University of Leeds in spring 2017 about translanguaging and ESOL.

James Simpson is an applied linguist specialising in the teaching and learning of languages in migration contexts and in the intersection of new technology, literacy and social justice. Most of his research has taken place in the North of England, and he has also carried out work in South Asia. He is currently a coinvestigator on a large project studying urban multilingualism, the Translation \& Translanguaging project (AHRC, 2014-2018). Recently he has developed an interest in participatory arts-based and co-produced approaches to migrant language education. James manages a vibrant online discussion forum, ESOLResearch, chairs the Migrant English Support Hub in Leeds and is a member of the steering group for the NATECLA National ESOL Strategy for England. He is the co-author (with Melanie Cooke) of ESOL: A Critical Guide (OUP, 2008), the co-editor (with Anne Whiteside) of Language Learning and Migration: Challenging Agendas in Policy and Practice (Routledge, 2015), and the coeditor (with Emilee Moore and Jessica Bradley) of Translanguaging as Transformation: The Collaborative Construction of New Linguistic Realities (Multilingual Matters, in preparation). In Applied Linguistics more generally he is the editor of the Routledge Handbook of Applied Linguistics (2011), serves on the committee of the British Association for Applied Linguistics (BAAL), and chairs the organising committee for the BAAL 2017 conference. Earlier in his career he worked as an English language teacher in a range of contexts in Europe, the Middle East and the UK. He has an MA in ELT (University of Essex, 1996) and a PhD in Applied Linguistics (University of Reading, 2004). Upon completion of his $\mathrm{PhD}$ he joined the Language Education team in the School of Education, University of Leeds, where he now leads the Language Education Academic Group.

\section{Interview}

Interviewer: James, can you tell me what projects you are currently working on?

Simpson: Right, well thank you Stefan. The main project I'm working on right now is called TLang; it is Translation and Translanguaging: Investigating Linguistic and Cultural Transformations in Superdiverse Wards in Four UK Cities, which is a bit of a mouthful, so we call it TLang. It is a large four year project, funded by the Arts and Humanities Research 
Council (AHRC), led by Professor Angela Creese at the University of Birmingham. There are teams working on this project in Birmingham, Leeds, London, and Cardiff. I am one of the co-investigators on the project, leading the Leeds end of the work. We're three years into the project, finishing up the last of the four phases of data collection and preliminary report writing, and we're moving into a period where we're looking at dissemination, public engagement, looking forward to the next things, thinking about the final report, thinking about the final conference, and so on. It has been a pure pleasure to work on it. It has been absolutely wonderful, not least because of the team that we have developed, across the project as a whole, but also here in Leeds. One of the things I've learned on the work is the joy of collaborative partnerships and how collaborative partnerships with team members can just make the ideas blossom. It is a very fruitful and very productive way of working. We have been working with key participants, who are in four spheres of activity; business and enterprise was the first one, heritage was the second, sport was the third, and the fourth one is law. These are four very different areas of life and experience, but actually a tremendous amount of overlap between each one. Our key participant in the business phase was a selfemployed translator and community interpreter and that was her business. But she did a lot of work with advocacy groups. In the law phase, we've been working with an immigration lawyer, who offers free drop-in legal advice and also has an advocacy role. So, there's a sort of crossover there. The key participant that we were working with in our heritage phase was a Roma community activist, who was trying to set up heritage related activities for a relatively new migrant group, for whom established tangible and even intangible heritage was not really on the radar. She ended up becoming an advocate for the Czech and Slovak speaking Roma population in Leeds. So rather strangely and perhaps unpredictably, there has been a lot of crossover between the different phases and the work.

So it is translation and translanguaging, cultural and linguistic transformations in superdiverse wards. We are working with two very current terms in sociolinguistics and the sociolinguistics of migration; one is superdiversity, the other is translanguaging. Superdiversity is quite a contested term. You might ask: what's wrong with just more diversity? There are fairly well established and interesting, worthwhile critiques of the notion of superdiversity. But we hold on to the notion, because of the idea that superdiversity implies the diversification of diversity. We're not just witnessing diversity across ethnic, cultural, and linguistic lines, but we are seeing now in contemporary urban Leeds and other cities, and also 
increasingly in rural areas, a diversification of diversity, suggesting that it pertains in a sort of cross-cutting way. People are coming to the UK with not just different linguistic, national, and ethnic backgrounds, but also economic backgrounds, motives for migration, different processes of insertion into employment and into the housing market, and so on and so forth. They are all very much varied, compared to more established patterns of migration, which we might have seen a generation or two ago.

It is an interesting idea and it helps us to understand that contemporary communication is not something that happens between people who are co-members of established communities in any way necessarily. So it disrupts the notion of community, which is a very well established notion in sociolinguistics in the study of language and society, and it brings us to the idea that what we're witnessing is languages and cultures in contact. In the TLang project, we're using the notion of the 'contact zone', which was an idea proposed by Marie Louise Pratt in the early 1990s, who recognized that what you don't have in and what you're not witnessing in the study of contemporary language use is the organic development of languages and varieties within a speech community or even discourse communities. What you're witnessing is what happens when very different cultures and languages and groups come into context. So, working with this idea of the contact zone and the multiple contact zones leads us to the idea that what we are seeing in language use is a multilingualism, which can be explained through the developing theoretical lens of translanguaging, which is the other key construct that we're working with in the project.

The easiest and most straightforward way of understanding translanguaging is that it is similar to the notion of code-switching and you can explain the same phenomena through an understanding of multiple language use as code-switching, as you can through translanguaging. Translanguaging privileges the user, it orients towards the user perspective. So the idea is that when people switch between languages, when they are in these fluid movements between languages it is not that they are consciously saying: "right now I'm speaking English, and now I'm speaking Spanish", or "in this domain I speak English at work and I speak Spanish with my family at home". Empirically, it is a lot more complex than that. We see that when people do develop multilingual practices, the shifts between societally recognised languages are very, very fluid. It is not sort of cut and dried, which suggests that what people are doing is drawing upon a linguistic repertoire and the linguistic repertoire that 
they have developed over the years, through contact with friends, family, schooling etcetera, contains elements that are recognisably from different 'languages' [languages in inverted commas], but are brought together and are deployed in interaction as appropriate to that interaction and what it requires. There has been some interesting research in cognitive linguistics more recently and in psycholinguistics, such as Aneta Pavlenko's 2014 book, which puts forward an understanding that bilinguals are more than two separate monolinguals, and that a way of conceptualising individual multilingualism is with reference to the linguistic repertoire: people draw upon a multilingual language system, deploying their repertoire as appropriate, and as far as they are able, depending on the contingencies of the context.

But we can extend the idea of translanguaging beyond translingual translanguaging and we can think about translanguaging between varieties of the same language and you can think about that very easily when you think about your own language use. We talk to people differently depending on who they are and who we are, depending on our relationships with them, and often that's a very sort of fluid shift between registers, between varieties and so on. So we've developed this idea of translingual translanguaging, of interlingual, between languages, and intralingual, within the same language, but across registers and varieties. Increasingly we're thinking about other transes, so transdiscursive translanguaging, transsemiotic translanguaging and that leads us to think about how translanguaging operates in the broader intellectual sphere and how it relates to transdisciplinary work that is going on and how the study of language in applied linguistics and sociolinguistics relates to other areas of study, e.g. arts based practice, the use of other semiotic resources for meaning making and we are becoming increasingly interested in this area of work.

Interviewer: Thank you very much for this insightful answer. Before we move on to the next question, can you tell us about the various outlets you have published your work relating the TLang project on?

Simpson: The main place where you can read our work is actually our website ${ }^{1}$, we have a working paper series, which is worth looking at. All of our project reports for the four cities have been published as working papers. Some of them are rather longer than papers. I think our latest one ran to around 40000-50000 words. They have been written up as peer-reviewed, 
publishable quality. We're very proud of them. You can also read early drafts there of various papers that have been published subsequently in journals, in working papers, in collection from conferences and so on. On the website we also have a blog${ }^{2}$, a very active blog that is widely read and we're very proud of that blog. It's a different type of academic publishing and something that we've all enjoyed very much. So an opportunity to talk about something in a shorter space for a more public audience. We're involved in the final stages of editing the 'Routledge Handbook of Language and Superdiversity', so the overall editors are Adrian Blackledge and Angela Creese. I am co-editing the section on 'Superdiversity and Education' with my colleague Melanie Cooke, who is at King's College in London, and that's coming out later on in 2017. We have a lot of publications in the pipeline; so chapters in edited collections, papers forthcoming in journals. Together with Emilee Moore, who is a visiting scholar from the Autònoma in Barcelona, and Jessica Bradley, who is our doctoral researcher on the project, I am editing a book about translanguaging and transformation, looking at the processes and the relationships and the products that emerge, when carrying out research into translanguaging and when our work and the work of others, from a language perspective, comes up against and joins in with work from other disciplines. So the sort of the productive relationships, the productive processes that emerge when people work across boundaries and disciplines.

Interviewer: Thank you James. My next question is: how does your research relate to policy and practice?

Simpson: The overall message of the TLang project is that people communicate multilingually and that people draw upon a multilingual repertoire to get things done in private, social, but also in public life. So it is emphasising and privileging multilingualism as a resource. So often in policy circles, multilingualism and the use of languages other than English is regarded as a problem. We only have to look at education policy, where English is very much the only game in town in policy circles and users of languages other than English, when they come into formal education, they are regarded quite often in policy institutionally and also in national policy as a problem to be dealt with. We've got these EAL (English as an Additional Language) students that have to be dealt with somehow. One of the implications of the TLang project and other work on multilingualism and multilingualism in education, for example, is that peoples' languages and peoples' multilingualism can be regarded and should 
be regarded as a resource, something that can be used productively in all sorts of spheres. So that is the sort of overall message.

Focusing in a little bit: my own background is in adult ESOL, the teaching and learning of English for adult migrants who are learners of English in English dominant countries. I was an ESOL teacher for a while before I started working in universities, and since the end of 2003 I have been researching the teaching and learning of English for adult migrants at the level of classrooms, but also in policy, and I have become increasingly interested in the interface between ESOL policy and classroom practice. One of the reasons we're so pleased to be involved in the TLang project is that I thought that the findings about contemporary urban multilingualism could inform ESOL practice, materials, curriculum, syllabus development, and I still think that. One of the things that we're working on quite actively is to bring together the findings from the TLang project and ESOL practice. The point is that through a lot of observations and a lot of interviews with teachers, it became very clear to me that teachers and the field of ESOL are very aware in fairly general terms of the challenges which their students face outside classrooms: students need to find a job, students need to a place to live, students need to get a roof over their head, students' lives are very precarious often. So it is a constant struggle, childcare is an issue, etcetera, they have to navigate the benefit system, or negotiate how to pay bills, and so on. What was missing, I think, was a detailed, in-depth understanding of the actual interactional realities of peoples' daily lives. What happens outside classroom? To develop that understanding you have to work with multilingual people in the area. You have to follow them out to the places and spaces where they live and work. You have to watch them interact. You have to record them and transcribe the interaction and so on, which is time consuming, difficult work. It implies prolonged engagement with participants. It implies an awful lot of work to prepare data for analysis and to do analyses, but a very fruitful outcome of that is this, as I am suggesting, this developing understanding of how people actually interact, drawing upon their language resources, but also their other semiotic resources. Translanguaging doesn't stop at language; it encompasses other modes of semiosis. Developing an understanding of how interaction actually operates should then fold back into ESOL practice and this is really actually very much where my work is going at the moment. How can research inform multilingual pedagogy for adult migrant language education? 
Interviewer: Thank you for this answer. Speaking about ESOL: what are your thoughts on the trajectory of ESOL provision in the UK, on a national scale, but also, as we're here in Leeds, on a local scale?

Simpson: ESOL is an interesting area of adult education and it attracted a lot of attention, one way or another, in policy circles, really since the late 1990s, and prior to the 1990s, in the UK anyway, it was really not on the policy radar. ESOL developed fairly informally as a field. It's quite interesting to track the different trajectories of adult ESOL - language in migration contexts - compared to the international EFL industry - English as a Foreign Language. EFL is typically being fairly well resourced, there are very well established qualifications and frameworks, if we think about the Cambridge exam and so on. Publishing in EFL is big business. EFL textbooks keep the publishing houses going I think. ESOL is a sort of poor relation to EFL, and always has been. It's interesting for me to see how it is all language education, it's all English language education, but two quite separate, different fields with different histories and different sorts of cultures in a way. Anyway, ESOL, in the 2000s, under the Blair government was encompassed in a large, relatively well resources policy called Skills for Life policy, an adult education policy. It became one of three Skills for Life; along with adult literacy and adult numeracy, ESOL was a Skill for Life. Alongside the Skills for Life policy, the National Research and Development Centre (NRDC) for adult literacy and numeracy was set up, which was sort of the research arm of Skills for Life, and it was set up to inform the policy. My very first ESOL research, as a research fellow, was on a large NRDC project called the Effective Practice Project and it is published as ESOL Effective Teaching and Learning, working here in Leeds with Mike Baynham and in London with Celia Roberts and Melanie Cooke. ESOL then, as I said, was fairly well resourced and at the peak at the Skills for Life policy, it was something like half a million people signed up for a state funded ESOL class, normally through a college of further education. ESOL has never been free for all people at the point of arrival in the country, which is what we advocated and what I continue to advocate. The sooner people are in an ESOL class, the less likely it is that their learning progression will be slowed and they become the long term residents who struggle with access to the dominant language in the country. But in the early 2000s it was fairly well resourced and it was available for people who needed it largely. Since about 2006, 2007, and increasingly since 2010, the field and access to classes has been progressively restricted to smaller and smaller, and narrower and narrower groups. So these days it is very hard to get on 
a state funded ESOL class, unless you are in receipt of particular work related benefits, or you have a certain status as a particular type of refugee.

Rather counter-intuitively and somewhat paradoxically, today in Theresa May's post Brexit vote government, it is actually a field that is attracting more funding than it has done in recent years. For example, there is a fund for proving language education for Syrian migrants that has been put into place and local providers of ESOL, if they are clever and intelligent, can tap into these funding sources and put on classes, which over the past few years haven't been able to run. So there is slightly less reliance on the voluntary sector, slightly less reliance on the third sector and doing things for free, than there has been in recent years. It is still a very fragmented field. It is still massively under-resourced it is still very much ignored and undervalued in national policy. The teachers' organisation NATECLA (National Association for Teaching English and other Community Languages to Adults) has recently developed a draft strategy for ESOL, a national strategy, which is a start; it's a good thing. It will help to confer a bit of coherence onto the field. Wales has a national ESOL strategy, so does Scotland. England doesn't, but hopefully NATECLA's efforts will eventually appear in national policy, the national strategy for the provision of migrant language education for adults will develop. It needs a national strategy. The field needs to be coherent. It needs to be joined up. People need to know where they can go to access an English class and how that English class will help them progress to other areas of English language study and then on to other areas of education and employment. With an incoherent unjoined up, and fragment picture, people are really at a loss, where to go, what to do, who to call on, when they realise, as they inevitably do, that access to the dominant language of the country is a huge advantage as a migrant.

In Leeds, the picture is actually very interesting: Leeds City College have got a very active and intelligent coordinator of ESOL. The head of their ESOL provision, Stephen Woulds, has worked extremely hard to build up the provision. Things are actually looking quite good at Leeds City College. They still have long waiting lists, they are still not able to put on classes in community centres, precisely where everybody needs to be gaining access to a class. So a lot of people in the city still need to rely on the voluntary sector, the charities, the private sector providers sometimes, the third sector providers of ESOL classes, until they can get into class at the college, or if there is an alternative form of provision for them. 
Working with Leeds City Council, I chair a group called MESH - Migrant English Support Hub, which aims to, in some way, join up provision of ESOL across the city. We have developed an online resource called Language in Leeds ${ }^{3}$ (LEL), and the idea is that every single ESOL provider in the city, which is about 50 or 60 , possibly more, different organisations. Each of those organisation has a presence on the website, each of them post the information about the classes they have on offer and what the restrictions are and who's eligible, and where they are, and the times, and so on. All that information is available on one website, which is constantly updated. Previously, people relied on photocopied lists of ESOL providers, which were inaccurate, out of date, and really not very helpful at all. MESH developed from research that I led actually in 2010-2011, we called it the HENNA project ${ }^{4}$; the Harehills ESOL Needs Neighbourhood Audit project. It was a pilot project supported by Leeds City Council back in 2010, when ESOL provision ceased to become part of national policy, national responsibility, as Skills for Life policy came to an end and responsibility was handed over to the local councils. The first thing that the council did was to commission this pilot project, to conduct an audit of ESOL provision and the need for ESOL, and we carried that out in Harehills. We found lots of different providers hosting ESOL classes and one of the main findings was that provision was completely incoherent. It was fragmented; it was unconnected. People would typically say, when they were told that there were 20 providers of ESOL in Harehills, they said: "really, where are they?" Or one provider wouldn't know that a different provider was running a class out of the same building but the next day, and so on. It was a shambles. The idea was that the pilot project would roll out across the whole city, so a whole citywide mapping exercise would be carried out and that would form the basis of a coherent ESOL policy.

Of course, between the time of commissioning the project in early 2010 and actually carrying it out in 2010-2011, there was a change of government. It was the time when the conservative liberal-democrat coalition came in and austerity measures ruled the day, including savage cuts to local government. Many, many people lost their jobs and many policies, such as the coordination of ESOL, were completely put on hold. So in the background, over the years, a group of us, who are people in the council, but also other providers and other people with a stake in ESOL, have worked quite hard, on a shoestring, to develop and maintain some sort of coordination of the field. We gained some funding to continue the mapping exercise. We 
gained some more funding to develop the websites and finally, after some few years, this work is being recognised at higher levels of local government policy. People are realising that it has value and, increasingly, it is being supported by the local council. So it is becoming more into the Leeds City Council fold as it were. So in the future, I hope that we'll be able to achieve more sustainable funding for the coordination of ESOL provision in Leeds and that our organisation, MESH, and the LEL website, will have a centrally established role as this coordinating body. But also, we have ambitions to provide resources for teachers, to provide online access to self-study materials for people who are on waiting lists, and so on. So that's a small success story in the context of a very difficult period for adult migrant language education in the UK.

Interviewer: Thank you ever so much James. We have time for one last question: Among which groups of migrants is the demand the highest and what are the barriers to accessing ESOL provision?

Simpson: That's an interesting question and it is a question that is always raised and typically, the response of politicians and also some providers is that it is women who haven't benefited particularly from education, who are stuck at home, these are seen as sort of hard to reach groups. I think that is a bit of a cliché, it becomes a bit of cliché. It certainly becomes a problematic cliché when people start assuming that they are being prevented from attending ESOL classes by the family and the idea is floated in policy that we should make attendance at ESOL classes compulsory. Compulsory ESOL classes, I don't think is the way to go. The key to breaking down barriers to access to ESOL classes is the provision of appropriate classes. Classes which do the right thing, in places where people can get to them, where they are accessible, for free, because people are often not rich and paying for an English class is pretty low on the budget priority, and doing very important things, like making sure there is appropriate childcare. So what you do to encourage people who haven't previously managed to get to an ESOL class is to make sure that the provision is appropriate, is in a place where people can get to, and they can actually do it, because there is somewhere they can leave the child while they are studying for example. Then, we would be pushing at an open door, because there is no sense at all that people are unwilling to learn English. There might be people who are unwilling to learn English, but I have never met any. All new arrivals understand the importance of gaining access to English, which is the dominant language of 
the UK. It's much more a case of "How do I find an ESOL class that I can get to, that's affordable or free, that's near where I live, that's right for me?"

Another group of people who find it hard to get to an ESOL class are people who are employed. It's difficult to find ESOL classes that are held at the right time, that are flexible enough to cope with shift patterns, peoples' unpredictable working patterns, that's something that is being somewhat neglected in policy, I think. The provision of workplace ESOL lessons I think is something that can be looked at. And when we're talking about compulsion, then one of my ideas is that we should insist that employers, who employ over a certain number of people, should provide ESOL classes. We can compel to employers to pay people a minimum wage, we should be able to compel employers to provide learning opportunities for their employees. Because it won't happen on its own. It hasn't happened on its own. The notion of the group is problematic, I think, and typically, ESOL students have been lumped together in groups. These are 'Muslim mothers', a favourite group of David Cameron's and also Tony Blair's actually. People who don't have literacy in a first language, they are a group, people on low grade employment might be another group, and so on. But, if we scratch the surface, we deal with individuals; individual lives, individual concerns, needs, wants, desires, and so on, and individual circumstances, which either prevent or enable them to gain access to an ESOL class.

But the other thing that I would add to that is that it is one thing making sure that people can get into a class, what happens in those classes is quite another thing and that brings me back to my original points about appropriate provision, recognising the multilingual realities of peoples' daily lives, and I would advocate very strongly for a multilingual ESOL pedagogy. There are colleagues in London who are working on this: for example, Dermot Bryers and colleagues at English for Action. He has published his work with Melanie Cooke and Becky Winstanley in one of my edited collections. There are colleagues in various places, who are working on the ideas of bringing in findings from research into translanguaging, for example, into ESOL practice and developing practice which draws upon peoples' already existing, very rich linguistic resources in the learning process. There is also a place, of course, for critical ESOL pedagogy, whereby students are encouraged to reflect upon, what you might loosely call reflect upon, the circumstances of their own marginalisation. A tendency in government funded ESOL provision is to ignore or deny the sort of critical dimension. What we tend to 
have when people are sent to an ESOL class for example, because they have been deemed unemployable, because of their language level, is a very reductive, very instrumental, very banal sort of job skills training type of ESOL and that doesn't really do it for people. People need a broader base, and I would also maintain that people need to devote criticality in their learning. So critical pedagogy, maybe inspired by critical literacy educators, such as Paulo Freiro, has a place in ESOL, and I would like to see more of that in practice and being spread.

Interviewer: Thank you for your time James.

Simpson: Thank you.

\section{References}

Baynham, M. (2007). ESOL: Effective teaching and learning. NRDC: London.

Blackledge, A., \& Creese, A. (Eds.) (forthcoming). Routledge handbook of language and superdiversity. London: Routledge.

Cooke, M., Winstanley, B. \& Bryers, D. (2015). Whose integration? A participatory ESOL project in the UK. In J. Simpson \& A. Whiteside (Eds.), Adult language education and migration: Challenging agendas in policy and practice (pp. 214-224). London: Routledge.

Pavlenko, A. (2014). The bilingual mind and what it tells us about language and thought. Cambridge: Cambridge University Press. https://doi.org/10.1017/cbo9781139021456.009

Pratt, M. L. (1991). Arts of the contact zone. Profession, 33-40.

\footnotetext{
1 See: http://www.birmingham.ac.uk/generic/tlang/index.aspx

2 See: https://tlangblog.wordpress.com/

3 See: https://www.lel.help/

4 See: http://www.education.leeds.ac.uk/research/projects/henna-project
}

\section{Author information}

Stefan Vollmer is a doctoral researcher at the University of Leeds, who is currently researching the digital literacy practices of newly arrived Syrian refugees in Leeds. Stefan has a background in language education and applied linguistics. He has taught at primary, secondary, and tertiary level in Germany, the UK, and the US.

Email: S.M.Vollmer@,leeds.ac.uk

To cite this article:

Vollmer, S. (2017). An interview with James Simpson on translanguaging and ESOL. Bellaterra Journal of Teaching \& Learning Language \& Literature, 10(1), 85-96. DOI: http://dx.doi.org/10.5565/rev/jt13.720

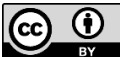

